\title{
Recognizing the best intervals for hydraulic fracturing using a new fracability index
}

\author{
Hamed Amiri ${ }^{1} \cdot$ Ahmad Ramezanzadeh $^{1}$ (D) Mohamadali Chamanzad ${ }^{1} \cdot$ Mohammadreza Parhizgar $^{2}$
}

Received: 7 December 2020 / Accepted: 26 April 2021 / Published online: 7 May 2021

(c) The Author(s) 2021

\begin{abstract}
The first phase of any hydraulic fracturing (HF) operation is to select carefully the best layers and wells based on a specific set of criteria. Selecting HF candidates plays a pivotal role in achieving the desired objective such that any attempt to execute this treatment fails without performing comprehensive studies in this regard. In this paper, data from 3 wells in a fractured carbonate reservoir in one of the biggest oilfields of Iran are studied for selecting the best HF candidate. Of these wells, which are comprised of 45 evaluated layers, the best candidate wells/layers are selected from a geomechanical point of view. Initially, a new fracability index appropriate for carbonate reservoirs, namely total fracability index (TFI), is defined. This index integrates mechanical properties and horizontal stresses into an equation. In the next step, four main criteria, namely layer thickness, TFI, natural fractures state (including orientation and density), and fracture confinement, are employed to choose the candidate layers in the wells. Lastly, having used these criteria and analytic hierarchy process, candidate intervals are selected and a hydraulic fracturing simulation model (P3D) is used for evaluation.
\end{abstract}

Keywords Hydraulic fracturing $\cdot$ Fracability $\cdot$ P3D stimulation $\cdot$ Geomechanical modeling $\cdot$ Analytic hierarchy process (AHP)

\section{Introduction}

Hydraulic fracturing is one of the most renowned stimulation techniques to increase production and improve the recovery factor in various reservoirs. In the hydraulic fracturing process, the weakest interval in the hydrocarbon-bearing reservoir is injected with the fracturing fluid at high pressure until the fracture is nucleated in the formation. Some operations and phenomena such as drilling, matrix acidizing, and sanding usually cause formation damage. This phenomenon, which is ubiquitous in most carbonate reservoirs of Iran, has

Ahmad Ramezanzadeh

aramezanzadeh@shahroodut.ac.ir

Hamed Amiri

amiiri.hamed@gmail.com

Mohamadali Chamanzad

alichamanzad@gmail.com

Mohammadreza Parhizgar

rezaparhizgar@gmail.com

1 Shahrood University of Technology, Shahrood, Iran

2 National Iranian South Oilfields Company, Ahwaz, Iran detrimental effects on wells' productivity (Zoveidavianpoor et al. 2012). The issue of candidate selection is one of the most challenging problems in different fields of engineering, particularly in the petroleum industry. In this industry, the cost of some operations like hydraulic fracturing is very high such that choosing the wrong candidates can be a total waste of time, effort, and capital. Moreover, neglecting the candidate selection context will culminate in the failure of the whole operation and the absence of a proper candidate selection procedure. Consequently, many problems such as unwanted growth of fracture to upper and lower layers, insufficient fracture conductivity, and fracturing fluid leakoff may arise (Roshanai Heydarabadi et al. 2010). The task of candidate selection is done to recognize the layers that need a lower pressure for the fracture to be created and also to show the potential for considerably enhancing the well productivity (Hashemi et al. 2013).

The history of recognizing the practical criteria for candidate-well selection almost started in 1970, once Howard and Fast explained eight criteria for candidate-well selection (Howard and Fast 1970). Hashemi et al. (2013) present the development of a locally written interface to select automatically specific zones for special operations like HF (Hashemi 
et al. 2013). Although this technique can be applied for an unlimited number of zones and wells, there is no criterion for the correctness of the method. Krasey calculated the current skin factor and determined the production rate after reaching a stable point and in a skin factor of -4 for the wells (Krasey 1988). In this study, the dimensionless productivity index was considered as a proper criterion for selecting candidates well. Martin and Economides (2010) used fractured well dimensionless productivity index as a function of proppant number. Permeability, skin factor, the production history of the wells, oil, and gas in place volume, reservoir pressure, and fracture containment were evaluated in the study of the Middle East reservoirs. Pre- and post-fracturing production performance of the well was modeled and compared in another study (Heydarabadi et al. 2010). Different criteria for selecting the candidate layers are layer thickness, average water and oil saturation, distance to oil-water contact, Young's modulus, the magnitude of stress in the layer, and stress contrast of a layer with the adjacent ones. Besides, productivity index, skin factor, permeability, and bottom hole pressure have been assessed to select candidate wells (Hashemi et al. 2012). On the other hand, having adequate oil in place, a proper amount of porosity, and low permeability necessitates coming up with a well-designed hydraulic fracturing treatment (Shadizadeh et al. 2009). Fiho and Castro compared the performance of a neuro-fuzzy system and used a genetic fuzzy system for selecting wells for hydraulic fracturing based on the knowledge acquired from operational data (Filho and Castro 2014).

Bangestan reservoir, because of its sufficient amount of oil in place and the good quality of porosity with low permeability and flowing capacity, is a good candidate for a hydraulic fracturing operation (Shadizadeh et al. 2009). In this paper, various layers of Sarvak formations in the Bangestan reservoir were studied to identify the most reliable candidate intervals for hydraulic fracturing operation. Decisive factors and criteria controlling the hydraulic fracture were identified based on previous studies. Additionally, the total fracability index (TFI) was used to filter out the numerous layers and zones. Finally, layer thickness, natural fracture condition, fracture containment capacity, and TFI were assumed as the main criteria for selecting the best interval for the operation. Validation of introduced criteria is essential not only as producers but also as fracture geometry. Therefore, a hydraulic fracturing simulation model (i.e., P3D) was used for the evaluation of these criteria. In the following sections, the main criteria for taking into account and their importance for fracturing purposes are discussed.

\section{Reservoir condition}

Three wells in one of the oilfields located in the southwest of Iran were collected and used to select the candidate layers and wells for hydraulic fracturing treatment. Bangestan reservoir, as a fractured carbonate reservoir, was studied for this purpose. A geomechanical model in the target wells was constructed. The model consists of elastic and strength properties, pore pressure, and magnitude of stress. Furthermore, the orientation of natural fractures and the direction of maximum horizontal stress were obtained using analysis of image logs.

Horizontal in situ stress was evaluated using the poroelastic equation. In two wells (B and C), calibration of stresses was only done using failure criteria and observation of breakouts in the wells (Zoback 2010). In well A, calibration of the estimated stresses is done through the results of XLOT in the interval of 3512.5-3516 m and available image log from 3318 to $3510 \mathrm{~m}$. Pore pressure and RFT, stress calculation, and XLOT, the upper and lower limit of mud pressure were estimated using Mohr-Coulomb and Mogi-Coulomb. Induced fractures observed in the image log in well A are shown in Fig. 1. As can be seen, these fractures have been well predicted by the MEM model. However, no shear failure (breakout) is observed in the logging interval, which is also confirmed by both criteria. Also, the stress regime in this well is normal. Elastic dynamic parameters of the rock were obtained through shear and compression wave velocities. Also, the static values of Young's modulus, Poisson ratio, and rock strength parameters were estimated via empirical relations used in the carbonate reservoirs of Iran.

Induced drilling fractures (tensile fracture) show dip inclinations varying from 80 to $90^{\circ}$ and dominant strike trends of 80 to $100^{\circ}$, which is along the direction of maximum horizontal stress. Therefore, the orientation of the minimum horizontal stress in well A is N-S. In wells B and $\mathrm{C}$, the orientation of minimum horizontal stress is $\mathrm{N} 37 \mathrm{~W}$ and $\mathrm{N} 65 \mathrm{~W}$, respectively, which is aligned with the trend of Zagros folding in the southwest of Iran. Also, the faulting regime in these wells is obtained to be mainly strike slip.

Well fractures analysis is shown in Fig. 2. The azimuth of the fractures in well $\mathrm{C}$ is between 30 and 70 . Also, the minimum horizontal stress is in the N53E direction. Therefore, the hydraulic fracture and natural fracture direction will have a contrast less than $45^{\circ}$. In well $\mathrm{B}$, the angle between the hydraulic fracture and natural fractures is the same as that of well C. Meanwhile, the angle between hydraulic fracture and natural fractures in well $\mathrm{A}$ is more complicated and varies point by point. Evaluation for well no A was done zone by zone.

Analysis of ultrasonic borehole imager (UBI) shows that there are 205 open fractures in well C, of which 169 


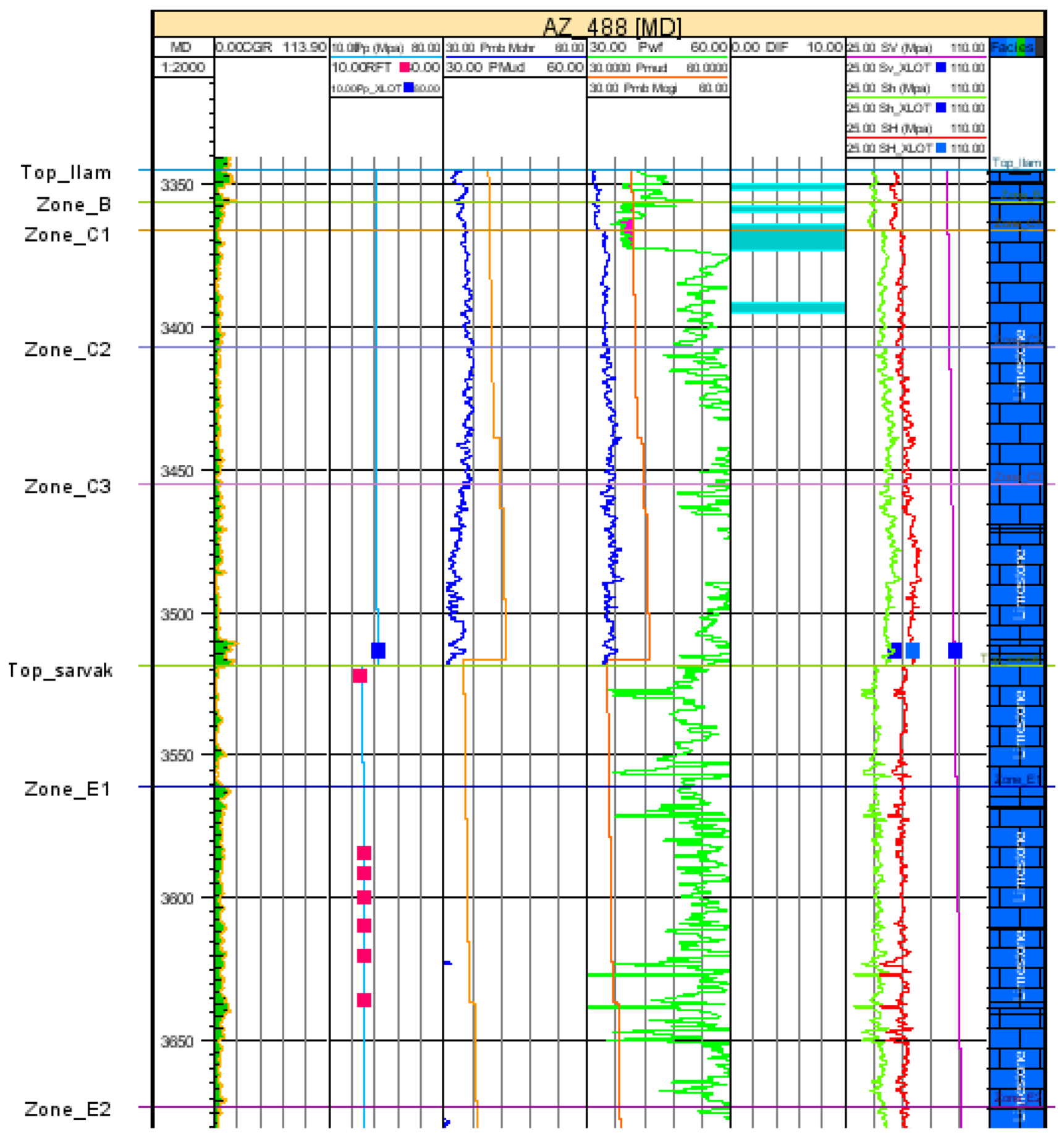

Fig. 1 Induced fractures observed in image log and calculated stresses in well A

are discontinuous open fractures, 35 possible open fractures, and 1 open fracture. In wells A and B, however, the number of observed natural fractures in image logs is low. Characteristics of natural fractures are briefly shown in Table 1. The possible interaction between natural fractures and the hydraulic fracture was assessed based on the data in Table 1.

\section{Criteria for HF Selection}

\section{Containment of HF}

For the hydraulic fracture to be propagated in the interval of interest, surrounding layers must be able to stop the fracture from vertical propagation. Fracture containment is the 

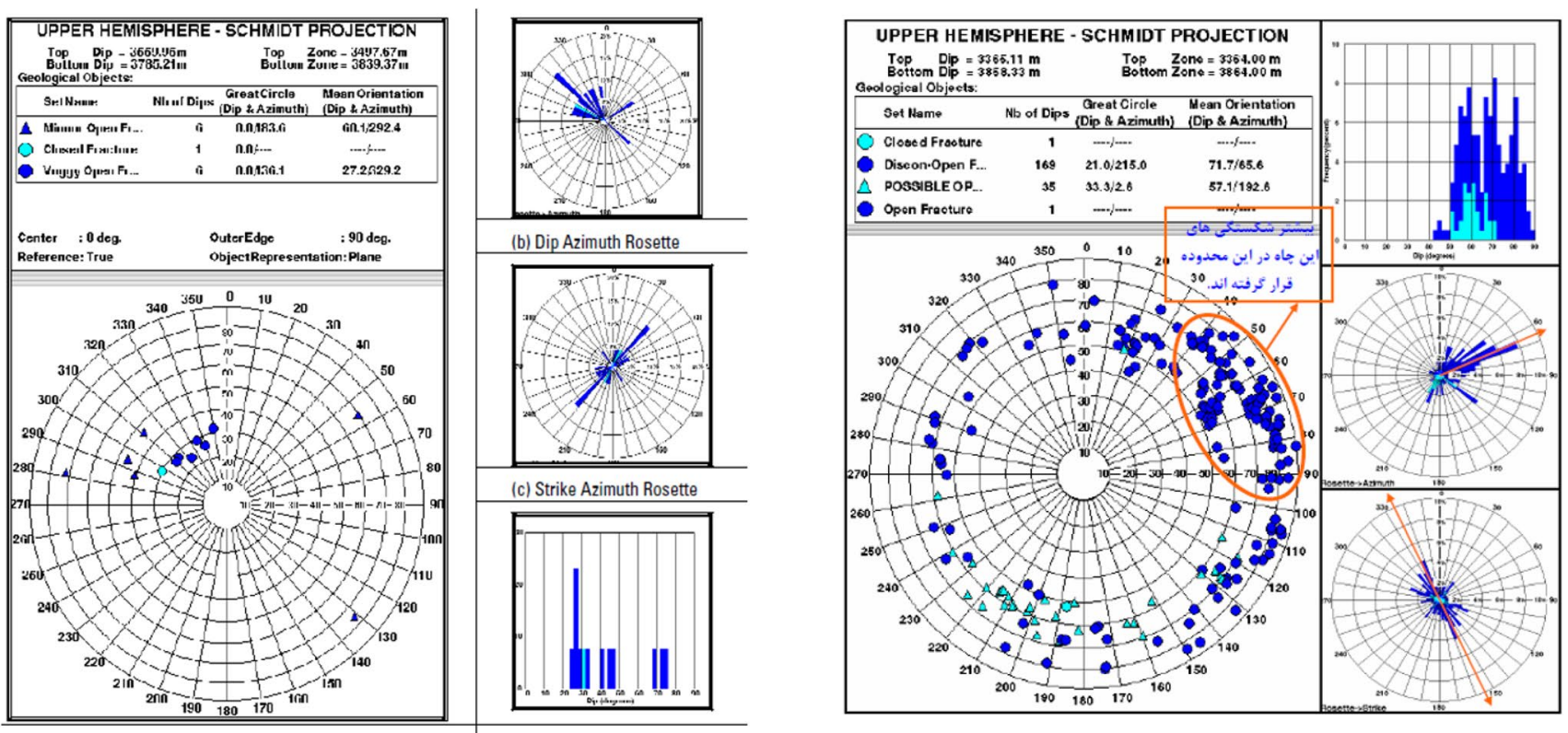

Fig. 2 Natural fractures analysis in well no B (left) and A (right)

Table 1 Characteristics of natural fractures in the studied wells

\begin{tabular}{lcllll}
\hline Well & $\begin{array}{l}\text { Number of } \\
\text { fractures }\end{array}$ & Average dominant strike & $\begin{array}{l}\text { Inclination } \\
\text { range }\left(^{\circ}\right)\end{array}$ & $\begin{array}{l}\text { Average dominant } \\
\text { dip azimuth }\end{array}$ & $\begin{array}{l}\text { Maximum } \\
\text { horizontal stress } \\
\text { direction }\end{array}$ \\
\hline A & 4 & N70E-N80E & $70-80$ & N20W-N10W & N90E \\
B & 13 & N30E-N70E & $20-40$ & N60W-N20W & N53E \\
C & 205 & N25W & $50-90$ & N65E & N25E \\
\hline
\end{tabular}

capability of an interface to act as a barrier in the way of propagating fracture. This can have disastrous effects on the results of treatment (Heydarabadi et al. 2010). The factor that can control the fracture growth and limit its unwanted propagation to adjacent layers is a strong minimum horizontal contrast between the target zone and surrounding ones. Besides, if there is an adequate difference in elastic parameters and/or strength properties between the layers, the vertical growth of the fracture might cease. In the same vein, adjacent layers must have a higher value than the layer of interest so that hydraulic fracture may be restricted in the target interval (Michael and Kenneth 2013; Sarmadivaleh and Rasouli 2010).

\section{Interaction between natural fractures and hydraulic fracture}

Once a hydraulic fracture reaches a preexisting fracture, three scenarios may occur based on the approach angle between them (Zangeneh et al. 2014). The first scenario, which is called Cross, happens when propagating fracture crosses the natural fracture without being considerably diverted. The second scenario (i.e., Offset), in which a hydraulic fracture is not able to intersect the natural fracture, is possible if fluid pressure is sufficient to reinitiate it in the direction of natural fracture. Finally, the third scenario is the Arrest, which is expected when the pressure within the fracture is not high enough to cross. Therefore, in this case, the hydraulic fracture stops after reaching the natural fracture. The difference between horizontal stresses and the approach angle are two main parameters determining which one of the mentioned scenarios may occur. The summary of these studies is shown in Table 2 (Rahman et al. 2010; Taleghani and Olson 2014; Zangeneh et al. 2014; Zhou et al. 2008).

\section{Total fracability index (TFI)}

The total fracability index integrates fracability and horizontal stresses into an equation. Fracability is an index that can be used to recognize the intervals in which the chance of success is good and hydraulic fracturing treatment may be proficiently executed. However, as there is no general equation to evaluate the fracability, a fracability index is defined in different situations according to the probable failure mechanism, geological 
Table 2 Qualitative scale rating based on horizontal stress contrast and approach angle

\begin{tabular}{lll}
\hline Approach angle $\left(^{\circ}\right)$ & $\begin{array}{l}\text { Horizontal stress contrast } \\
(\mathrm{MPa})\end{array}$ & State \\
\hline No natural fracture & Indifferent & Moderate \\
$\theta<45^{\circ}$ & Indifferent & Very poor \\
$45^{\circ}<\theta<60^{\circ}$ & $\Delta S<10$ & Poor \\
$45^{\circ}<\theta<60^{\circ}$ & $\Delta S>10$ & Good \\
$\theta>60^{\circ}$ & Indifferent & Very good \\
\hline
\end{tabular}

setting, geomechanical background, and also other key parameters that could affect the final operation outcomes (Fang and Amro 2014; Fu et al. 2015; Guo et al. 2015; Mullen and Christia 2012; F. Zhang et al. 2015). Both the knowledge of fracture mechanism and the knowledge of geological setting are required to obtain a mathematic equation for evaluating fracability in a reservoir. Also, determining geomechanical parameters such as vertical and horizontal stresses and mechanical and strength properties is another significant point that must be considered in this regard. Overall, the fracability index is proposed to combine determining factors and parameters whereby the best choices for the treatment can be identified (Zhang et al. 2015).

As there is no universal equation for fracability, different studies have proposed an appropriate equation by considering lithology and the particular conditions of the reservoir of interest (Guo et al. 2015; Jin, Shah, Roegiers, and Zhang 2015). Other parameters such as Young's modulus and uniaxial compressive strength (UCS) could have marked effects on the hydraulic fracture. In this respect, UCS can be regarded as a parameter that plays a prominent role in selecting the candidate layers (Bai 2016).

In the present study, at first, a correlation analysis was conducted to extract a relationship between elastic and strength parameters. The values estimated in the geomechanical modeling were used for correlation analysis. Regarding the normal distribution and the high number of the needed data, the Pearson correlation between the parameters was established one by one. The results of the analysis reveal that there is a strong positive relationship between Young's modulus and other elastic and strength parameters except for the internal friction angle (Table 3). Therefore, these two parameters were selected and Eq. (1) was considered for calculating the fracability. Briefly, fracability shows the ease of creating a hydraulic fracture in a given formation. This index, generally, is a function of rock strength, although other factors may have a role as well. Equation (1) is established based on the correlation of the study data and other relations proposed in the literature with respect to the conditions of carbonate reservoirs.

$\mathrm{FI}=\frac{E_{n}+2 B_{r}}{3 \operatorname{Sin}(\varphi)}$

$B=\frac{W_{\mathrm{QFM}}}{W_{\mathrm{Tot}}}+\frac{W_{\mathrm{Carb}}}{W_{\mathrm{Tot}}} \approx \frac{W_{\mathrm{QFM}}+W_{\text {Calcite }}+W_{\text {Dolomite }}}{W_{\mathrm{Tot}}}$

$E_{n}=\frac{E_{\max }-E}{E_{\max }-E_{\min }}$

$\varphi=26.5-37.4\left(1-\phi-V_{\text {shale }}\right)+62.2\left(1-\phi-V_{\text {shale }}\right)^{2}$

where $B_{r}$ is brittleness obtained from the mineralogical analysis and $E_{n}$ is the normalized Young's modulus (Jin et al. 2015). Plumb's correlation (1994) is used to evaluate the friction angle (Plumb 1994). To the best of our knowledge, no relation has been proposed for estimating the internal friction angle of rocks based on log data. In this regard, Plumb's relation for estimating this parameter is based on shale content and porosity for sedimentary rocks. As can be seen, the fracability is in direct proportion to brittleness; however, the fracability index decreases as either Young's modulus or internal friction angle increases. Also, the internal friction angle decreases by increasing porosity and clay content, and fracability increases consequently. Nevertheless, layers having high clay content are not appropriate candidates due to their ductile nature.

It is well proven that magnitude of minimum horizontal stress and contrast between the horizontal stresses are of crucial importance in the candidate selection. Hence, a more comprehensive form of fracability (i.e., TFI) is presented in Eq. (5). Equation (5), as one of the innovative aspects of this article, is based on AHP and ranking the importance of sub-criteria in the utilized questionnaires. FI is the fracability calculated by Eq. (1); $\sigma_{h}$ and $\Delta S$ are minimum horizontal stress and horizontal stress contrast, respectively; and $W_{1}$, $W_{2}$, and $W_{3}$ are coefficients calculated by the analytic hierarchy process (AHP). It is of note that the sum of all three $\mathrm{W}$ indexes is equal to 1 .

Table 3 Correlation results between elastic and strength parameters

\begin{tabular}{|c|c|c|c|c|c|c|}
\hline Parameter & Poisson ratio (PR) & Bulk modulus (K) & Shear modulus $(\mathrm{G})$ & $\begin{array}{l}\text { Uniaxial compres- } \\
\text { sive strength (UCS) }\end{array}$ & $\begin{array}{l}\text { Tensile strength } \\
\text { (TS) }\end{array}$ & $\begin{array}{l}\text { Internal friction } \\
\text { angle }\end{array}$ \\
\hline Young's modulus E & 0.94 & 0.99 & 0.99 & 0.83 & 0.79 & 0.43 \\
\hline
\end{tabular}


$\mathrm{TFI}=W_{1} \frac{\mathrm{FI}-\mathrm{FI}_{\min }}{\mathrm{FI}_{\max }-\mathrm{FI}_{\min }}+W_{2} \frac{\sigma_{\mathrm{hmax}}-\sigma_{h}}{\sigma_{\mathrm{hmax}}-\sigma_{\mathrm{hmin}}}+W_{3} \frac{\Delta S-\Delta S_{\min }}{\Delta S_{\mathrm{max}}-\Delta S_{\min }}$

\section{Results}

After constructing MEM and determining proper criteria, the AHP method was implemented to select candidate layers in the wells. AHP is one of the well-known and most commonly used multi-criteria decision-making (MCDM) methods by which one can determine the relative importance of both qualitative and quantitative criteria in a problem (Badri 2001). Generally, decision making by this method is done through three steps (Dağdeviren 2008): (1) building a hierarchy tree, (2) determining the relative importance of criteria and alternatives, and (3) synthesizing the priorities.

AHP breaks a complicated problem down into a hierarchy tree in which different elements such as goal, criteria, and sub-criteria are connected. The main goal is placed at the top of the hierarchy, criteria in the middle, and alternatives at the bottom (Albayrak And Erensal 2004) (Fig. 3). In this study, to select candidate wells and layers, different steps of the AHP method were performed using the Expert Choice software.

Some experts on hydraulic fracturing were asked to fill out a questionnaire to determine the relative importance of criteria and sub-criteria. In the AHP method, pairwise comparisons between the criteria are made according to a

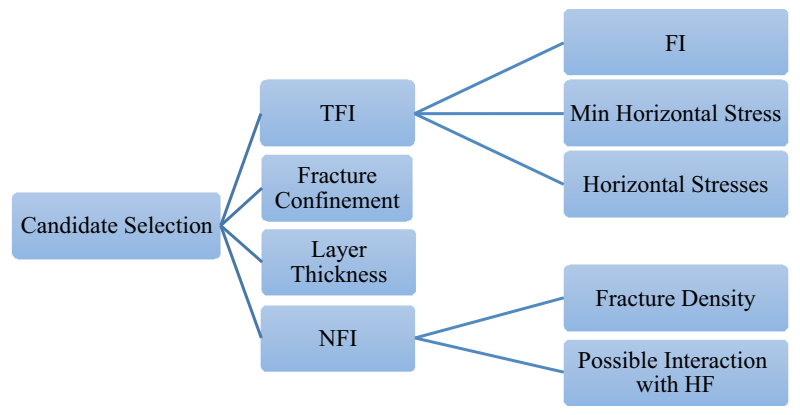

Fig. 3 Hierarchy tree for selecting candidate layers for HF standard scale (Greco et al. 2005). After doing the calculation using AHP, the coefficients in Eq. (5) are determined as follows:

$\mathrm{TFI}=0.64 \frac{\mathrm{FI}-\mathrm{FI}_{\min }}{\mathrm{FI}_{\max }-\mathrm{FI}_{\min }}+0.1 \frac{\sigma_{\mathrm{hmax}}-\sigma_{h}}{\sigma_{\mathrm{hmax}}-\sigma_{\mathrm{hmin}}}+0.26 \frac{\Delta S-\Delta S_{\min }}{\Delta S_{\mathrm{max}}-\Delta S_{\min }}$

Sub-criteria of TFI are fracability index, minimum horizontal stress, and horizontal stress contrast. Based on the results of the questionnaire, the fracability index is the first rate of importance and minimum horizontal stress is the least. Since there are numerous layers to study, first, potential layers were identified using Eq. (6). Next, potential layers were scrutinized and further analysis was conducted to select the final layer candidate in the wells.

\section{Discussion}

All four criteria were considered to select candidate layers and wells. Based on the results of the questionnaire, the coefficients of TFI, fracture containment, natural fracture index, and layer thickness were obtained to be $0.57,0.25,0.13$, and 0.05 , respectively. Regarding the coefficients of 0.83 and 0.17 for natural fracture density and interaction between fractures, it is suggested that according to experts' opinion, fracture density is more important than the interaction between the natural fracture and hydraulic fracture. The final outputs of criteria evaluation and candidate wells and layers selection in Sarvak formation are presented in Table 4.

Furthermore, hydraulic fracturing was simulated using the P3D method, which is a modified form of the two-dimensional PKN model. However, in the P3D model, the fracture height changes with stress and reservoir properties and thus affects the fracture width (Rahman and Rahman 2010). This method has been used for fracture evaluation in petroleum and coal reservoirs (Chamanzad et al. 2017; Zhang et al. 2016). To compare the results of simulation on different candidates, the fractures only are allowed to propagate up to $2 \mathrm{~m}$ away from each candidate's interval. Also, the same input parameters, including injection fluid type, proppant, and pumping rate, were used for all the simulations.
Table 4 Candidate wells and layers in Sarvak formation

\begin{tabular}{|c|c|c|c|c|c|c|c|c|}
\hline \multirow[t]{2}{*}{ Well } & \multirow[t]{2}{*}{ Layer } & \multirow[t]{2}{*}{ Depth } & \multirow[t]{2}{*}{ TFI } & \multirow[t]{2}{*}{ Fracture containment } & \multicolumn{2}{|c|}{ Natural fracture } & \multirow[t]{2}{*}{ Thickness } & \multirow[t]{2}{*}{ Score } \\
\hline & & & & & Density & Interaction & & \\
\hline B & E1 & $3589-3608$ & Very Good & Very good & Moderate & Moderate & Good & 0.173 \\
\hline B & E2-1 & $3659-3683$ & Very Good & Very good & Moderate & Moderate & Good & 0.173 \\
\hline B & E2-2 & $3700-3723$ & Very Good & Moderate & Moderate & Moderate & Good & 0.146 \\
\hline $\mathrm{C}$ & $\mathrm{G} 2-2$ & $3824-3837$ & Moderate & Excellent & Moderate & Moderate & Moderate & 0.104 \\
\hline A & E2 & $3730-3750$ & Good & Poor & Moderate & Moderate & Good & 0.082 \\
\hline
\end{tabular}


Figure 4 shows the simulation results for the first candidate layers in Table 4. Fracture geometry and conductivity of fracture are shown in this picture. A summary of all simulations is shown in Table 5 . The best parameter for comparison is the area of fracture multiplied by the fracture conductivity. Therefore, the simulation results (Table 5) are highly consistent with those of zone selection in Table 4.

According to Table 5, the first candidate (E1 in well B) has the largest area $\left(453 \mathrm{~m}^{2}\right)$ and the highest conductivity. However, the fracture height of the second candidate (E2-1) is relatively greater, but the fracture half-length is less and so the fracture area is slightly smaller than the first candidate. The quantity of fracture area multiplied by the conductivity is almost close to each other (Table 4) for the first and second candidates. The smallest half-length belongs to the fifth candidates due to the inadequate confinement of the fracture (caused by the low stress contrast) in these layers.

\section{Conclusions}

In this research, the total fracability index (TFI) was investigated for evaluating the fracability of a carbonate reservoir. This index is obtained based on the minimum horizontal stress, horizontal stress difference, Young's modulus, brittleness, and internal friction angle. AHP was used to evaluate TFI based on natural fracture index, layer thickness, and fracture restriction. Finally, the proposed criterion was validated through hydraulic fracturing simulation.

Considering the decreasing trend in the amount of hydrocarbon production in the oil fields, the need for a simulation method such as HF is indisputable. To this end, a local procedure for selecting proper well and layers should be developed for having a well-adopted operation in a carbonate reservoir. In this study, the total fracability index (TFI) was proposed by considering the most important parameters affecting the results of hydraulic fracturing in carbonate reservoirs and available data. The importance of each parameter was proposed in Eq. (6). Having employed this index and three other criteria (i.e., orientation and density of
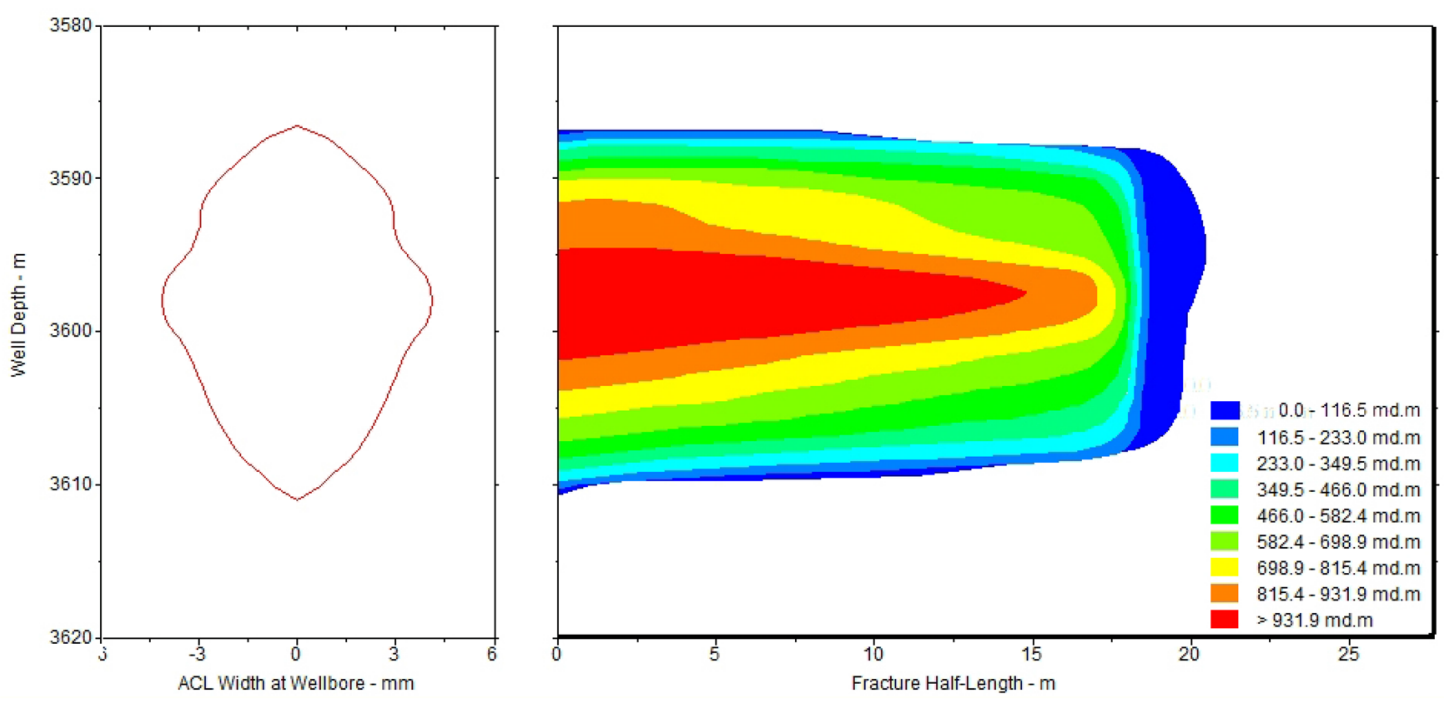

Fig. 4 Fracture width and conductivity contour of well B for an interval of 3589-3608 m

Table 5 Geometry and conductivity of fracture stimulation for candidate layers

\begin{tabular}{lllllll}
\hline Well & Layer & Fracture & & & \\
\cline { 3 - 6 } & & Max height $(\mathrm{m})$ & $\begin{array}{l}\text { Max width } \\
(\mathrm{mm})\end{array}$ & $\begin{array}{l}\text { Max half- } \\
\text { length }(\mathrm{m})\end{array}$ & $\begin{array}{l}\text { Max conductiv- } \\
\text { ity (md m) }\end{array}$ & $\begin{array}{l}\text { Area } \times \text { conduc- } \\
\text { tivity (md m }\end{array}$ \\
\hline B & E1 & 24 & 4.5 & 18.9 & 1164 & 289,423 \\
B & E2-1 & 26.1 & 4.5 & 17.3 & 1055 & 265,014 \\
B & E2-2 & 25.8 & 3 & 9.3 & 1143 & 184,655 \\
C & G2-2 & 17.2 & 2.5 & 16.6 & 694 & 116,077 \\
A & E2 & 20.8 & 2 & 10 & 845 & 87,659 \\
\hline
\end{tabular}


natural fractures as natural fracture index, fracture confinement, and interval thickness with coefficients $0.13,0.25$, and 0.05 , respectively), layers of three wells were investigated for selecting the most proper candidates by an equation. To assess the validity of the proposed fracability index and equation, a P3D model was employed to predict the length and height of fracture. The results represent a very well agreement between the proposed candidates and simulation.

Funding All authors certify that they have no affiliations with or involvement in any organization or entity with any financial interest or non-financial interest in the subject matter or materials discussed in this manuscript.

\section{Declarations}

Conflicts of interest The authors have no conflicts of interest to declare that are relevant to the content of this article.

Open Access This article is licensed under a Creative Commons Attribution 4.0 International License, which permits use, sharing, adaptation, distribution and reproduction in any medium or format, as long as you give appropriate credit to the original author(s) and the source, provide a link to the Creative Commons licence, and indicate if changes were made. The images or other third party material in this article are included in the article's Creative Commons licence, unless indicated otherwise in a credit line to the material. If material is not included in the article's Creative Commons licence and your intended use is not permitted by statutory regulation or exceeds the permitted use, you will need to obtain permission directly from the copyright holder. To view a copy of this licence, visit http://creativecommons.org/licenses/by/4.0/.

\section{References}

Albayrak E, Erensal YC (2004) Using analytic hierarchy process (AHP) to improve human performance: an application of multiple criteria decision making problem. J Intell Manuf 15(4):491-503

Badri MA (2001) A combined AHP-GP model for quality control systems. Int J Prod Econ 72:27-40. https://doi.org/10.1016/S09255273(00)00077-3

Bai M (2016) Why are brittleness and fracability not equivalent in designing hydraulic fracturing in tight shale gas reservoirs. Petroleum 2:1-19. https://doi.org/10.1016/j.petlm.2016.01.001

Chamanzad M, Ramezanzadeh A, Tokhmechi B, Norouzi H (2017) Comparison of different hydraulic fracture growth models based on a carbonate reservoir in Iran. J Chem Pet Eng 51(December):95-104

Dağdeviren M (2008) Decision making in equipment selection: an integrated approach with AHP and PROMETHEE. J Intell Manuf 19:397-406. https://doi.org/10.1007/s10845-008-0091-7

Fang C, Amro M (2014) Influence factors of fracability in nonmarine shale. In: European unconventional resources conference and exhibition 2014: unlocking European potential, vol 2. Society of Petroleum Engineers, Vienna, Austria, pp 1196-1202

Filho VJMF, de Castro AO, S. (2014) Selecting Oil wells for hydraulic fracturing: a comparison between genetic-fuzzy and neuro-fuzzy systems. Am J Oper Res 04(04):202-216. https://doi.org/10.4236/ ajor.2014.44020
Fu H, Wang X, Zhang L, Gao R, Li Z, ZhuXuLiXu XWQT (2015) Geological controls on artificial fracture networks in continental shale and its fracability evaluation: a case study in the Yanchang Formation, Ordos Basin, China. J Nat Gas Sci Eng 26:1285-1293. https://doi.org/10.1016/j.jngse.2015.08.034

Greco S, Figueira J, Ehrgott M (2005) Multiple criteria decision analysis: state of the art surveys. Springer, New York. https://doi.org/ 10.1007/b100605

Guo JC, Luo B, Zhu HY, Wang YH, Lu QL, Zhao X (2015) Evaluation of fracability and screening of perforation interval for tight sandstone gas reservoir in western Sichuan Basin. J Nat Gas Sci Eng 25:77-87. https://doi.org/10.1016/j.jngse.2015.04.026

Hashemi A, Shadizadeh SR, Zoveidavianpoor M (2012) A local computerized multi-screening of vast amount of data to select hydraulic fracturing candidates in iranian carbonate oil fields. Int J Comput Appl 975:8887

Hashemi A, Shadizadeh SR, Zoveidavianpoor M (2013) Selection of hydraulic fracturing candidates in iranian carbonate oil fields: a local computerised screening of zone and well data. In: International petroleum technology conference. International Petroleum Technology Conference, Beijing, China

Heydarabadi FR, Moghadasi J, Safian G, Ashena R (2010) Criteria for selecting a candidate well for hydraulic fracturing. Society of petroleum engineers-Nigeria annual international conference and exhibition 2010. NAICE 1:353-359. https://doi.org/10.2118/ 136988-ms

Howard GC, Fast CR (1970) Hydraulic fracturing. Society of petroleum engineers of AIME, New York, $\mathrm{p} 210$

Jin X, Shah SN, Roegiers JC, Zhang B (2015) An integrated petrophysics and geomechanics approach for fracability evaluation in shale reservoirs. SPE J 20:518-526. https://doi.org/10.2118/168589-PA

Krasey R (1988) High-grading fracture candidate selection. J Can Pet Technol 27:50-54. https://doi.org/10.2118/88-04-03

Martin AN, Economides M (2010) Best practices for candidate selection, design and evaluation of hydraulic fracture treatments. SPE Prod Oper Conf Exhib. https://doi.org/10.2118/135669-MS

Michael JE, Kenneth GN (2013) Reservoir stimulation. Wiley, New York

Mullen M, Christia T (2012) Fracability index-more than just calculating rock properties. SPE annual technical conference and exhibition, USA

Plumb RA (1994) Influence of composition and texture on the failure properties of clastic rocks. Soc Pet Eng Rock Mech Pet Eng 1994:13-20. https://doi.org/10.2118/28022-ms

Rahman MM, Rahman MK (2010) A review of hydraulic fracture models and development of an improved pseudo-3D model for stimulating tight oil/gas sand. Energy Sour Part A Recovery Util Environ Eff 32(15):1416-1436. https://doi.org/10.1080/15567 030903060523

Rahman MM, Aghighi MA, Ravoof SA, Syed AH (2010) Effect of natural fracture on hydraulic fracture propagation in naturally fractured geothermal reservoirs. World Geothermal Congress, pp. $25-29$

Roshanai Heydarabadi F, Moghadasi J, Safian GA (2010) Hydraulic fracturing in iran-lessons from four case histories. SPE Prod Oper Conf Exhib. https://doi.org/10.2118/136103-ms

Sarmadivaleh M, Rasouli V (2010) Simulation of hydraulic fracturing in tight formations. APPEA J 50(1):581-592

Shadizadeh SR, Habibnia BA, Syllabee R (2009) Investigation and selection of suitable layers in bangestan reservoir for hydraulic fracturing operation. Sci Iran 16(2 C):149-160

Taleghani AD, Olson JE (2014) How natural fractures could affect hydraulic-fracture geometry. SPE J 19(1):161-171. https://doi. org/10.2118/167608-PA

Zangeneh N, Eberhardt E, Bustin RM (2014) Investigation of the influence of natural fractures and in situ stress on hydraulic fracture 
propagation using a distinct-element approach. Can Geotech J 52(7):926-946. https://doi.org/10.1139/cgj-2013-0366

Zhang F, Zhang H, Yuan F, Wang Z, Chen S, Li C, Han X (2015) Geomechanical mechanism of hydraulic fracturing and fracability evaluation of natural fractured tight sandstone reservoir in Keshen Gasfield in Tarim Basin Fuxiang. SPE-177457-MS

Zhang X, Zhang S, Yang Y, Zhang P, Wei G (2016) Numerical simulation by hydraulic fracturing engineering based on fractal theory of fracture extending in the coal seam. J Nat Gas Geosci 1(4):319-325

Zhou J, Chen M, Jin Y, Zhang GQ (2008) Analysis of fracture propagation behavior and fracture geometry using a tri-axial fracturing system in naturally fractured reservoirs. Int J Rock Mech Min Sci 45(7):1143-1152. https://doi.org/10.1016/j.ijrmms.2008.01.001
Zoback MD (2010) Reservoir Geomechanics. Cambridge University Press, Cambridge

Zoveidavianpoor M, Samsuri A, Shadizadeh SR (2012) Development of a fuzzy system model for candidate-well selection for hydraulic fracturing in a carbonate reservoir. Society of Petroleum Engineers-SPE oil and gas india conference and exhibition 2012, pp 148-172

Publisher's Note Springer Nature remains neutral with regard to jurisdictional claims in published maps and institutional affiliations. 